\title{
Action of Runaway Electron Preionized Diffuse Discharges on Steel: Composition, Structure, and Properties
}

\author{
Mikhail Shulepov $^{1}$, Mikhail Erofeev ${ }^{1,2}$, Yuri Ivanov ${ }^{1,2}$, Konstantin Oskomov $^{1}$ and Victor Tarasenko ${ }^{1,2}$ \\ 1. Institute of High Current Electronics, Tomsk, Russia \\ 2. National Research Tomsk Polytechnic University, Tomsk, Russia
}

\begin{abstract}
In the work, we studied the effect of the plasma of a runaway electron preionized (REP) diffuse discharge (DD) on the composition, structure, and properties of ST3PS steel surface layers. Voltage pulses with an incident wave amplitude of up to $30 \mathrm{kV}$, FWHM of around $4 \mathrm{~ns}$, and rise time of around $2.5 \mathrm{~ns}$ were applied to the gap in an inhomogeneous electric field. The ST3PS steel specimens exposed to this type of discharge revealed changes in their defect subsystem, suggesting that the runaway electron preionized diffuse discharge provides surface hardening of the steel.
\end{abstract}

Key words: Runway electron preionized diffuse discharge, defect substructure, hardening of ST3PS steel.

\section{Introduction}

Research in the effects of a runaway electron preionized diffuse discharge (REP DD) on different materials is an urgent and interesting problem. This type of discharge is formed as nanosecond high-voltage pulses are applied to a gap with a cathode of small curvature radius; see the reviews $[1,2]$ and references therein. In a REP DD, the anode experiences complex action of several factors: (1) dense nanosecond discharge plasma with a specific power ranging to hundreds of megawatt per cubic centimeter in single pulse mode [3]; (2) a shock wave which was recorded with a calorimeter [1]; (3) optical radiation of different spectral regions, including UV, VUV, X-rays from the discharge plasma [4]; and (4) a super short avalanche electron beam (SAEB) with a wide energy range [1]. As a result, the surface of different metals is cleaned from carbon and oxidized in oxygen-containing gases $[5,6]$, and semiconductors change the type of conductivity [7]. According to [8], REP DD treatment

Corresponding author: Victor Tarasenko, professor, research fields: gas discharge and plasma physics. E-mail: VFT@1oi.hcei.tsc.ru. provides surface hardening of copper specimens supposedly due to the formation of a thin copper oxide film.

The aim of the work was to study the influence of the REP DD plasma on composition, structure, and properties of ST3PS steel.

\section{Experiments}

For the formation of a REP DD, we used a FPG-60 generator [9], the voltage pulses from which were applied to the discharge chamber. The generator was connected to a gas discharge gap of $7 \mathrm{~mm}$ via a $75 \Omega$ cable $4 \mathrm{~m}$ long. The incident voltage wave amplitude in the transmission line (75 $\Omega$ cable) was varied between $10 \mathrm{kV}$ and $30 \mathrm{kV}$. The anode was plane and was the electrode on which plates of ST3PS steel [10] were arranged being wiped with alcohol before exposure to a REP DD. The cathode was pointed and was made of steel. The chamber was filled with nitrogen with an impurity content of less than $0.01 \%$. The experiments were performed in repetitive pulsed mode at a pulse repetition frequency of up to $2 \mathrm{kHz}$. The number of pulses per specimen was normally $10^{5}$. 
The hardness and elastic moduli of the treated steel specimens were measured with a Berkovich indenter on a NanoTest 600 system. We analyzed loading-unloading curves at a load of 2, 5, 10, and 20 $\mathrm{mN}$ by the Oliver-Pharr method [11].

The steel structure was examined by transmission electron microscopy (TEM) on an EM-125 device. For the examination, foils of thickness $150-200 \mathrm{~nm}$ were prepared by electrolytic thinning. For this purpose, the initial and treated steel specimen were spark cut to obtain thin (around $300 \mu \mathrm{m}$ ) plates which were further mechanically thinned to around $100 \mu \mathrm{m}$ and electrolytically polished in an orthophosphoric acid-based reagent to around $0.2 \mu \mathrm{m}$.

\section{Results}

The experiments show that exposure of ST3PS steel to a REP DD, like that of copper [8], provides its surface hardening. The hardness of the steel is increased three times (Fig. 1). After $10^{4}$ pulses, hardening is also observed.

Electron microscopy of the ST3PS steel structure shows that in the initial state, the material is a polycrystalline aggregate. Its grains are fragmented into slightly misoriented $\left(1^{\circ}-3^{\circ}\right)$ volumes mostly of nonequiaxial shape (Fig. 2a). The lateral and longitudinal fragment sizes vary from 0.5 to $1 \mu \mathrm{m}$ and from 2 to $3.5 \mu \mathrm{m}$, respectively. In the fragment volume, a dislocation substructure is observed in the form of chaotically distributed dislocations (Fig. 2b) and dislocation networks (Fig. 2c). The scalar dislocation density determined by the intercept method [12] is found to vary in the range $(1-2) \times 10^{10} \mathrm{~cm}^{-2}$. In some cases, second phase particles are detected at grain boundaries. Interpretation of electron diffraction patterns [13] shows that these particles are iron carbide of composition $\mathrm{Fe}_{3} \mathrm{C}$ (cementite).

After irradiation, the steel remains to be a polycrystalline aggregate; however, its intragranular structure changes considerably. Firstly, an equiaxial fragmented substructure is formed at grain boundary

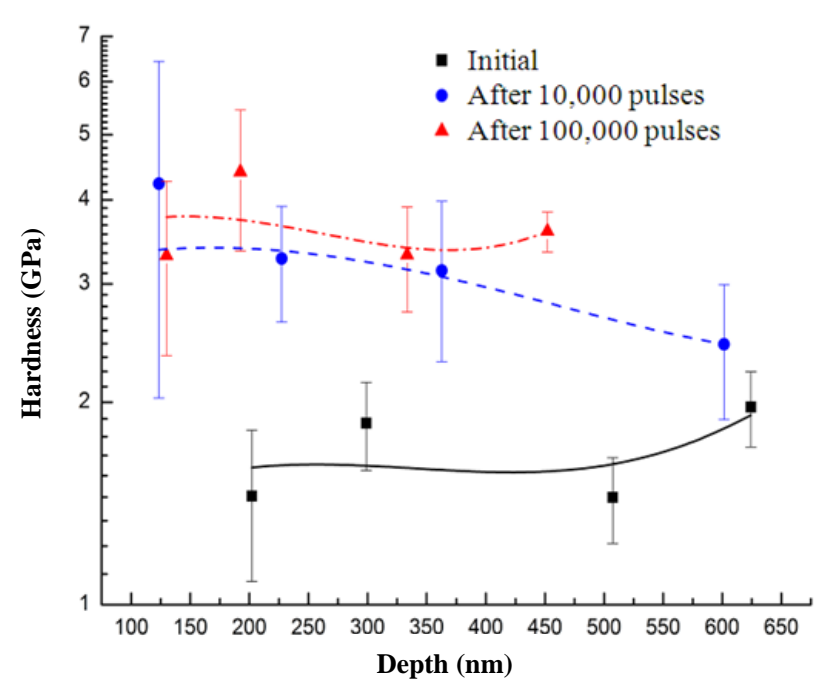

Fig. 1 Surface hardness of ST3PS steel before and after REP DD treatment.

junctions; the fragment size is $0.15-0.25 \mu \mathrm{m}$ which is much (5-10 times) less than that in the initial steel (Fig. 3a). Secondly, a band structure with a lateral band size of around $150 \mathrm{~nm}$ residing mainly at grain boundaries (Fig. 3b) is detected in addition to chaotic dislocations and dislocation networks. The evolution of the dislocation substructure involves a substantial increase in scalar dislocation density, the value of which is around $4.1 \times 10^{10} \mathrm{~cm}^{-2}$.

The foregoing facts suggest that the steel exposed to REP DD treatment is involved in plastic deformation.

Thirdly, the steel structure reveals bending extinction contours (marked by arrows in Fig. 4). The appearance of bending extinction contours in the steel structure unambiguously points to internal stress fields [12, 14], the sources of which (stress concentrators) in the examined material are interfaces of fragments and band substructure (Fig. 4a), grains (Fig. 4b), and second phase particles (Fig. 4c). The physical cause for bending contours is plastic deformation incompatibility of adjacent steel volumes, carbide particles, and adjacent $\alpha$-phase volumes [15].

Fourthly, regions of nanometer size $30-50 \mathrm{~nm}$ are observed at the grain boundary and fragment junctions in Fig. 5. The small size of these regions is evidenced also by a quasi-ring-structured electron diffraction 
Composition, Structure and Properties
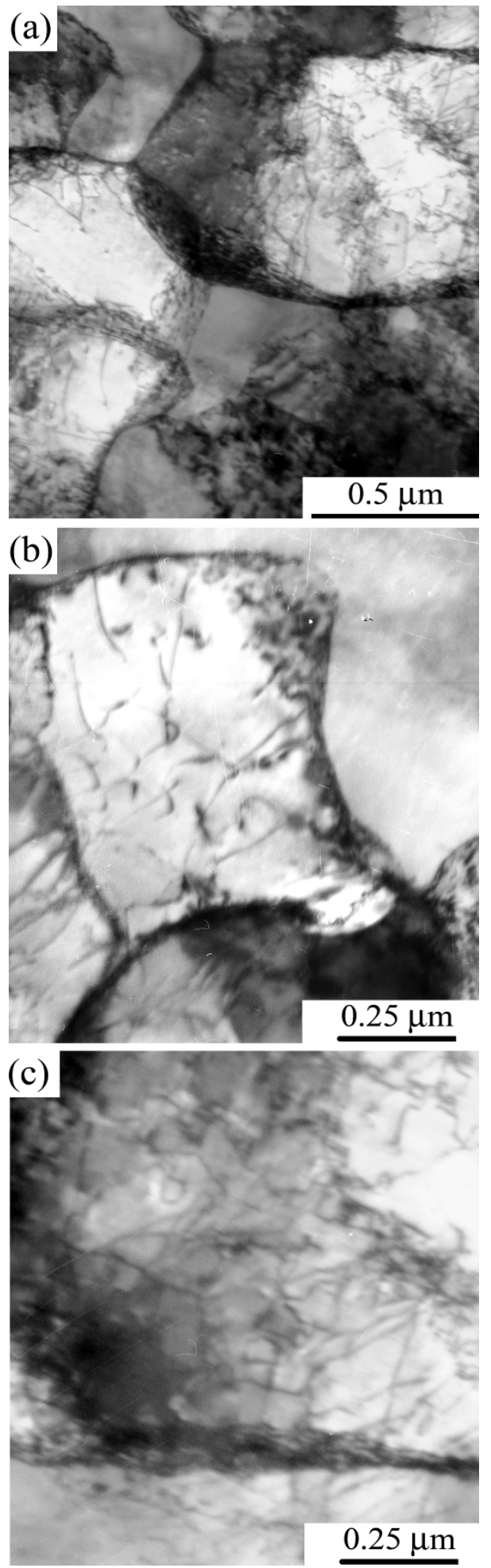

Fig. 2 TEM images of the initial ST3PS steel structure.

pattern of the foils in Fig. 5c. Analysis of the electron diffraction pattern presented in Fig. $5 \mathrm{c}$ points to the presence of reflections of the $\alpha$-phase and $\mathrm{Fe}_{3} \mathrm{C}$ carbide.
Fifthly, the frequency of occurrence of carbide phase reflections on electron diffraction patterns increases 2-3 times. This fact and the formation of two-phase regions of nanosized structure whose characteristic image is shown in Fig. 5 can be evidence that in the irradiated steel, a multi-stage process proceeds consisting in fracture (dissolution) of initial $\mathrm{Fe}_{3} \mathrm{C}$ particles, carbon redistribution in the grain volume, and repeated precipitation of carbide particles. Hence, exposure of ST3PS steel to REP DD irradiation initiates the processes that take place in the material in thermomechanical treatment.

\section{Conclusions}

Thus, the structural phase transformations revealed in the steel unambiguously suggest that treatment with a runaway electron preionized diffuse discharge produces thermomechanical action on the material. The character of dislocation substructure transformation
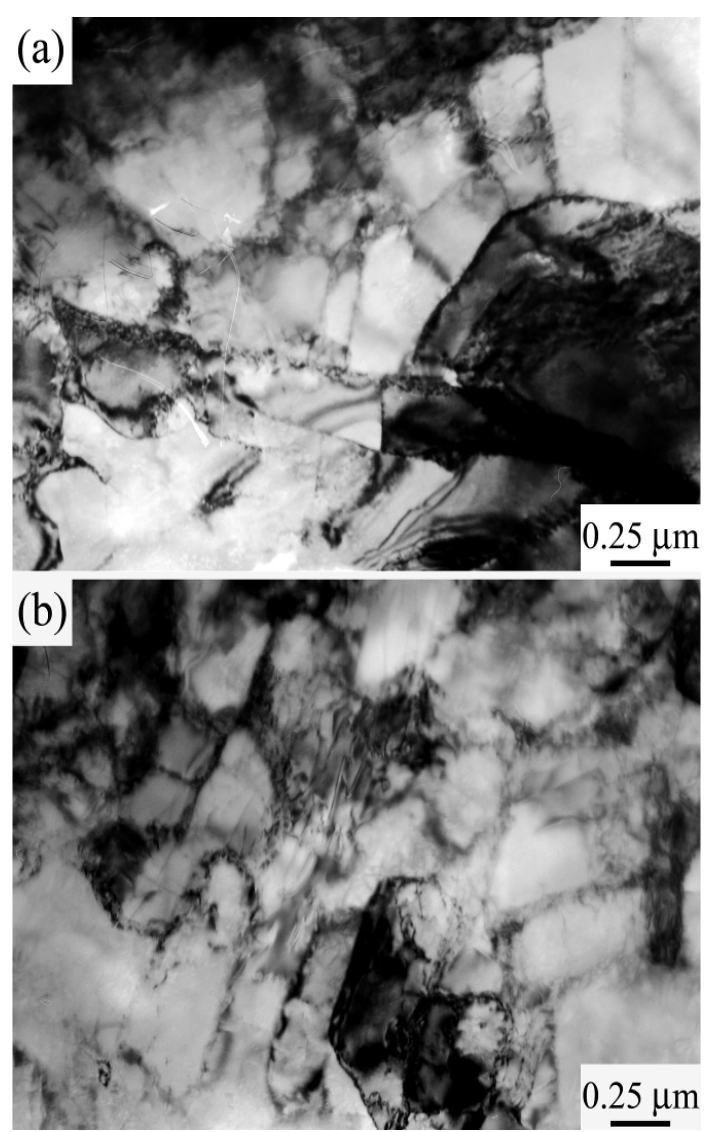

Fig. 3 TEM images of the defect substructure in irradiated ST3PS steel. 
Composition, Structure and Properties
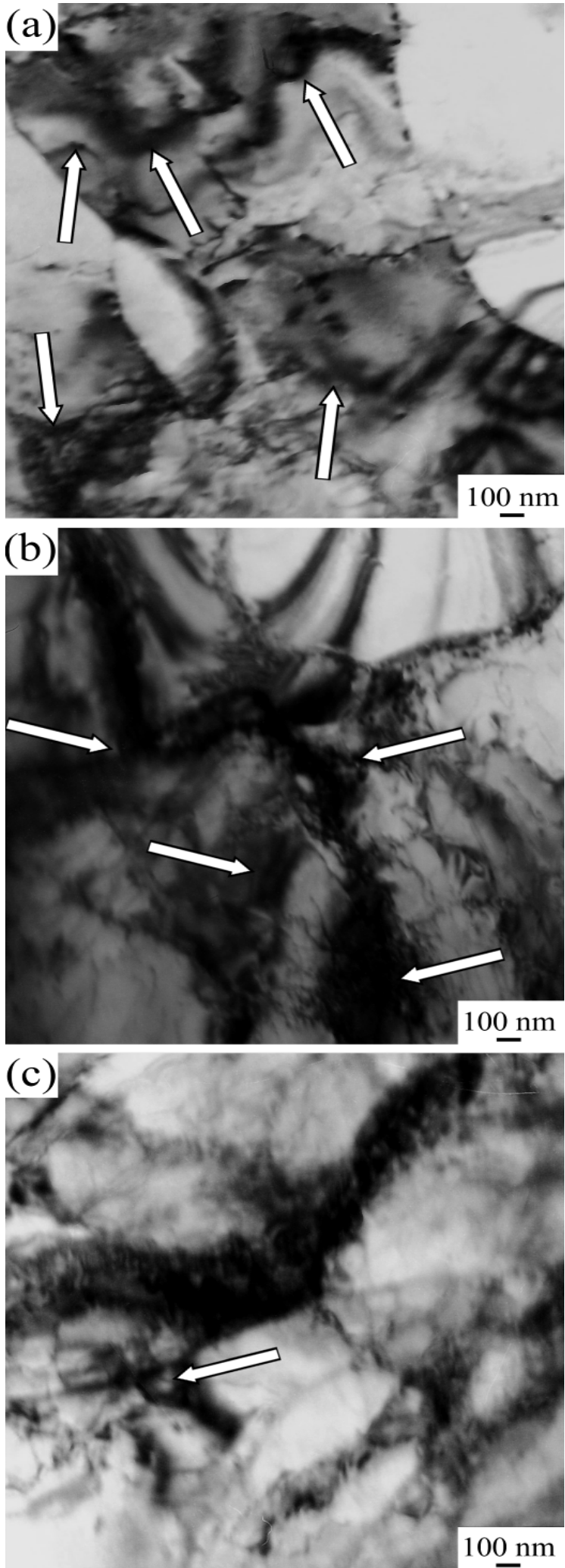

Fig. 4 Extinction contours on TEM images of thin foils for irradiated ST3PS steel. Shown by arrows are (a, b) extinction contours and (c) second phase particles.
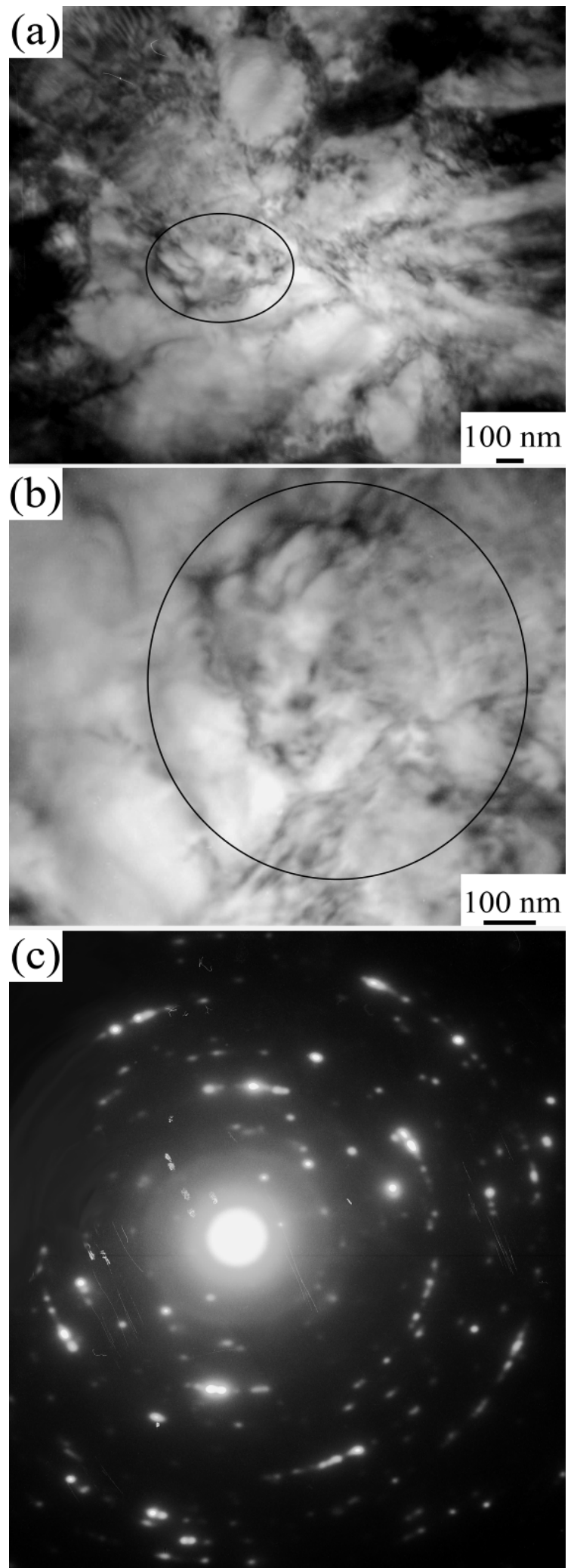

Fig. 5 Nanosized structure formed in irradiated ST3PS steel (marked by an oval): (a, b) bright fields and (c) electron diffraction pattern. 
(formation of additional interfaces, increase in scalar dislocation density, and formation of internal stress fields) and carbide subsystem transformation is indicative of the hardening effect of this type of treatment on the steel. Comparative analysis shows that the surface microhardness of the irradiated steel is up to three times higher than that of the initial steel.

\section{Acknowledgments}

The authors are thankful to Burachenko, A. G. for help in conducting the study.

This work was supported by Russian Scientific Foundation project No. 14-29-00052.

\section{References}

[1] Tarasenko, V. F., Baksht, E. K., Burachenko, A. G., Kostyrya, I. D., Lomaev, M. I., and Rybka, D. V. 2008. "Generation of Supershort Avalanche Electron Beams and Formation of Diffuse Discharges in Different Gases at High Pressure." Plasma Devices and Operation 16 (4): 267-98.

[2] Levko, D., Krasik, Y. E., and Tarasenko, V. F. 2012. "Present Status of Runaway Electron Generation in Pressurized Gases during Nanosecond Discharges." International Review of Physics 6 (2): 165-95.

[3] Alekseev, S. B., Gubanov, V. P., Kostyrya, I. D., Orlovskii, V. M., Skakun, V. S., and Tarasenko, V. F. 2004. "Pulsed Volume Discharge in a Nonuniform Electric Field at a High Pressure and the Short Leading Edge of a Voltage Pulse." Quantum Electronics 34 (11): 1007-10.

[4] Baksht, E. K., Lomaev, M. I., Rybka, D. V., and Tarasenko, V. F. 2006. "Study of Emission of a Volume Nanosecond Discharge Plasma in Xenon, Krypton and Argon at High Pressures." Quantum Electronics 36 (6): 576-80.

[5] Shulepov, M. A., Tarasenko, V. F., Goncharenko, I. M., Koval', N. N., and Kostyrya, I. D. 2008. "Modification of the Near-Surface Layers of a Copper Foil under the Action of a Volume Gas Discharge in Air at Atmospheric Pressure.” Technical Physics Letters 34 (4): 296-9.

[6] Tarasenko, V. F., and Shulepov, M. A. 2008. "Formation of Superpower Volume Discharge and Their Application for Modification of Surface of Metals." In Proceedings of SPIE. High-Power Laser Ablation VII, $70051 \mathrm{~N}$.

[7] Voitsekhovskii, A. V., Grigor'ev, D. V., Korotaev, A. G., Kokhanenko, A. P., Tarasenko, V. F., Shulepov, M. A. 2012. "A Change in the Electro-physical Properties of Narrow-Band CdHgTe Solid Solutions Acted upon by a Volume Discharge Induced by an Avalanche Electron Beam in the Air at Atmospheric Pressure." Russian Physics Journal 54 (10): 1152-5.

[8] Shulepov, M. A., Akhmadeev, Y. K., Tarasenko, V. F., Kolubaeva, Y. A., Krysina, O. V., and Kostyrya, I. D. 2011. "Modification of Surface Layers of Copper under the Action of the Volumetric Discharge Initiated by an Avalanche Electron Beam in Nitrogen and $\mathrm{CO}_{2}$ at Atmospheric Pressure.” Russian Physics Journal 53 (12): 1290-4.

[9] Efanov, V. M., Efanov, M. V., and Komashko, A. V. 2010. Ultra-wideband, Short Pulse Electromagnetics 9. New York, NY: Springer Science+Business Media, part 5.

[10] Zubchenko, A. S. 2003. Grades of Steels and Alloys. Moscow: Mashinostroenie, 784.

[11] Oliver, W. C., and Pharr, G. M. 1992. "Improved Technique for Determining Hardness and Elastic Modulus Using Load and Displacement Sensing Indentation Experiments.” Journal of Materials Research 7 (6): 1564-83.

[12] Utevsky, L. M. 1973. Electron Diffraction Microscopy in Metal Science. Moscow: Metallurgia, 584.

[13] Andrews, K., Dyson, D., and Kiown, S. 1971. Interpretation of Electron Diffraction Patterns. Moscow: Mir, 256.

[14] Hirsch, P., Howie, A., and Nicholson, R. 1968. Electron Microscopy of Thin Crystals. Moscow: Mir, 574.

[15] Ivanov, Y. F., Kornet, E. V., Kozlov, E. V., Gromov, V. E. 2010. "Quenched Structural Steel: Structure and Hardening Mechanisms." Siberian State Industrial Univ., Novokuznetsk, 174. 